\title{
Futuribles of learning 2030 - Delphi supports the reform of the core curricula in Finland
}

\author{
Tiina Airaksinen $^{1}$ (D) - Irmeli Halinen ${ }^{2} \cdot$ Hannu Linturi $^{3}$ \\ Received: 31 August 2016 / Accepted: 10 November 2016/Published online: 14 December 2016 \\ (C) The Author(s) 2016. This article is published with open access at Springerlink.com
}

\begin{abstract}
The Future of Learning 2030 Barometer was launched in 2009. It was ordered by the Finnish National Board of Education to support the reform of the core curricula and look beyond the contemporary interests. The aim of the Barometer is to acknowledge the futuribles of learning and take into consideration the possibilities and challenges that may affect the development of school, teaching and learning. The Barometer collects a diversity of arguments on the future so that the different perspectives and arguments can be balanced against each other. The Delphi method is used as a structured communication technique that takes advantage of new technologies and elements of social media. The aim is not a consensus but rather a multi-voiced view. The article describes the questions and meta-themes based on the analysis. It also describes how the Finnish National Board of Education has used the Barometer in the reforming of the core curricula.
\end{abstract}

Keywords Barometer - Basic education - Core curricula . Delphi $\cdot$ Future of learning $\cdot$ Futures map

Irmeli Halinen is an emerita in The Finnish National Board of Education.

Tiina Airaksinen

tiina.airaksinen@otavanopisto.fi

Irmeli Halinen

irmelihalinen9@gmail.com

Hannu Linturi

hannu.linturi@metodix.fi

Otava Folk High School, Mikkeli, Finland

2 The Finnish National Board of Education, Helsinki, Finland

3 Metodix Ltd, Helsinki, Finland

\section{The future of learning 2030}

The world around the school is complex, interdependent, rapidly changing, and uncertain. It is also increasingly digital. There is a need for thorough self-analysis of education systems. Does education help us face the challenges of the future? What kind of future does education construct?

Does education prepare pupils to good self-awareness, social responsibility, and adaptation to technology? Does it provide them with high-quality competences so that they are able to fulfil their potential in private life, at work, and in the society alike? The European Commission document 'A New Skills Agenda for Europe' [1] acknowledges that a broad set of competences is needed in the fast-changing world. High skills enable people to adapt to unforeseen changes and promote the transition to a balanced and sustainable way of living. How do we know what is really relevant in these changes? Are we able to look far enough in the future?

\section{Curriculum reform and the future}

Finland has just reformed (2012-2016) the national core curricula which guide the provision of education in municipalities and teaching and learning in schools. The renewal of the core curricula creates a common framework for the exploration of the change that takes place in the world and the surrounding society. The Finnish National Board of Education (FNBE) ${ }^{1}$ is the authority that leads state-level curriculum processes and is in charge of creating and making decisions concerning the national core curricula for all levels of education, except universities and polytechnics. It also supports local curriculum processes. In Finland, curriculum is the central tool for

\footnotetext{
${ }^{1}$ The Finnish National Board of Education (FNBE) is an autonomous state agency working closely with the Ministry of Education.
} 
teachers in planning and developing their own work. The purpose of the entire steering system is to ensure educational equality and quality, and to create optimal conditions for teaching and learning and for every student's development and well-being.

The Finnish culture of collaboration and trust became especially apparent in the extensive curriculum reform. The FNBE organised the process so that all changes were reflected on together with municipalities, schools, and teachers as well as with various stakeholders, and development efforts were taken in collaboration. An active concept of knowledge and learning was also central: new knowledge and understanding was built together [2]. The main goal of the reform was to create better prerequisites for successful teaching and for meaningful and enjoyable learning so that students would develop better competences for lifelong learning, active citizenship, and sustainable lifestyle.

An extremely important part of building understanding on the development of the society and the education system, and of creating visions for the future, was the barometer process, called The Future of Learning 2030. This was the first time such a tool was systematically used in the curriculum reform process. The Barometer offered totally new ways of providing opportunities for participation, knowledge-sharing, and collaborative design of visions. It was crucial for the FNBE to have the possibility to look beyond today's problems and conflicts. The objective was to recognise different development paths and to utilise the knowledge produced by the Barometer when making decisions on the core curriculum.

\section{Main features of the Future of Learning 2030 Barometer}

The current success of the Finnish education system (OECD: PISA Programme for International Student Assessment and PIAAC Programme for the International Assessment of Adult Competencies) is a result of choices and decisions made $15-30$ years ago. The same time perspective is used as the basis of the Future of Learning 2030 Barometer. The decisions of today have effects on the future tens of years from now. In terms of the school, it is necessary to identify such changes in the environment that have a significant impact on the forms of formal learning. What is also relevant, is how and when this change happens. Such qualitative progressions are anticipated in the Barometer that, unless discussed, result in opposition and conflicts between different interest groups. The Barometer is not merely about making use of possibilities of change, but also recognising the valuable and durable components of the historically shaped school of today.
The Barometer is based on genuinely open-ended questions. Larger questions peer behind elaborate theses on the future. What will the life of pupils be like in fifteen years? What is the school and teaching like? In what kind of a world does a young learner commute to school, if they commute at all? What if the school comes to the learner? What if we had to rethink the whole process of learning altogether?

The Barometer is used to draw an ever more accurate map of the future, with the speciality of many different possible futures, the futuribles. ${ }^{2}$ According to experts, some of these futures seem more probable than others. It is fascinating to explore the strengthening of some futures and the weakening of others. However, it is even more important to study and discuss the futures that are preferred or dystopian. Breakthroughs need to be made at least in the places where the probable and preferred paths cross. In the threat of the probable and non-preferred taking place at the same time, discussion and reflection is needed.

In the Barometer, the change is made visible, discussable, and operable, both in the case of fast and dramatic turns or slower and less noticeable changes that have more profound impacts. Change has a dialectical connection to the hopes, dreams, and fears of different operators in the society.

\section{Methodology}

The Future of Learning 2030 Barometer is designed to signal discontinuances and to create a decision basis for well-timed changes when they are needed. It is also used to initiate and spread discussions about the future of the school, learning, and teaching. The Barometer is a tool of qualitative forecasting and its documentation of possible directions of change and their arguments are used in discussions, research, and policy making.

The methodology of the Barometer relies on techniques of Futures Studies. The most central of them is the Delphi method. In addition, the Barometer makes use of the scenario technique $[4,5]$, the analysis of weak signals [6] as well as Causal Layered Analysis (CLA) created by Sohail Inayatullah [7, 8]. The methods are chosen in order to support the aim of longterm barometer research, which is to study especially the discontinuous future, where changes typical for the period are expected to happen in the objectives, working methods, and roles of the institution during the studied time frame. Weak signals are observed in annual theses analyses. During the second year of the Barometer futures table method was used

\footnotetext{
2 "If we do not know the consequences of our choices, our freedom to choose is an illusion. Hence, no freedom exists without forecasting." (Bertrand de Jouvenel) [3]
} 
to generate five scenarios which are introduced in the second year report [9].

\section{Argumentative Delphi}

The approach used in the Barometer is based on a variation of Policy Delphi, in which the anonymous argumentation of diverse and multidisciplinary experts is emphasised. An argumentative Delphi process typically begins with an issue that is either current or relevant in terms of the future. The ideal issue is an interesting, public, and unsettled matter, which however needs to be settled in the near future [10-16].

The method combines different Delphi techniques. The questionnaire comprises solely the theses on the future. They were tested and assessed with a two-round argumentative Delphi process, but the Barometer proper is executed according to the Real-Time Delphi concept. ${ }^{3}$ It means that the standardised Delphi questionnaire is in the panel's use in real time so that all the material is accessible the whole time and open to comments and editing of the answers. The special feature of the Barometer is that the questionnaire is answered every year so that the changes can be observed in sequences.

The study aims at collecting a diversity of arguments on the future so that the different perspectives and arguments can be balanced against each other. "Delphi may be characterized as a method for structuring a group communication process so that the process is effective in allowing a group of individuals, as a whole, to deal with a complex problem." Turoff's [16] definition emphasises the formation of knowledge and understanding within the process. In addition to gathering the different opinions, arguments, and perspectives, they need to be brought in dialogue with one another.

Delphi is used to study the probable and preferred future, and it is surveyed through the participants' arguments [17]. The web as an operating environment enables real-time dialogue among anonymous experts. Barometer-Delphi has a hypertextual structure in which every element has its own type (thesis, argument, scale) and relation to other elements. Within the limits of the structure of the Barometer, every expert can form their own statements and arguments of the matter during the whole process. They can vote for or against every statement and argument and also change their stand anytime they feel it is justified.

\section{Barometer-eDelphi}

The Barometer consists of four questionnaires and 48 theses on the future (Fig. 1). The theses are constructed so that each of them signals a wider range of phenomena than their

\footnotetext{
${ }^{3}$ Real-Time Delphi-method was developed in the UN Millennium Project (see http://www.millennium-project.org/millennium/RTD-method.pdf and http://www.realtimedelphi.net).
}

concrete content. The panellists have taken part in the Barometer seven times - annually ever since 2010. They assessed the probability and preferability of each thesis on a seven-point likert scale and then provided arguments for their assessments.

The future of the learning is approached through three panels. Into the so-called inside panel (39 panellists) were invited experts that deal with learning, teaching, and education directly in one way or another. Into the outside panel (34 panellists) were selected persons from other positions and fields of the society so that as many external interests and as much knowledge as possible become included in the inspection. In addition to the inside and outside panels, there is a socalled challenger panel, which also comments on the theses and which comprises mostly of developers of the school field (teachers and other school personnel) as well as members of interest groups such as parents and persons of trust in the school administration.

The differences between the panels help reflect on the interest variance among the groups. Following the Delphi technique, each panellist is grouped according to their expertise and interests. Expertise in administration, research, teaching as well as working and business life are separated from each other. Similarly, the interests are divided into four societal sectors: business life, public sector, associations and organisations as well as home and its surroundings.

The Barometer utilises the eDelphi software (http://edelfoi. fi), in which the researcher (Delphi manager) has three different working modes in their use (questionnaire, results, discussion). They can open and close these in different combinations so that they support the panel's communication and knowledge formation. The panellists have the opportunity to comment each other's comments in real time, which results in shorter and longer dialogue [9, 17]. The long-term nature of the Barometer enables the learning processes where dialogue chains deepen panellists' understanding on the matter. The panellists develop their overall perception while providing other panellists tools for developing theirs. Anonymity ensures that the experts can change their opinions without losing their authority or dignity. The special task of the Delphi managers is to provide the knowledge that rises from the analyses for the experts to use.

\section{The theses categorise futures thinking}

The dimensions of each thesis are probable, preferred, improbable, and non-preferred (Fig. 2). These are coordinates in which preferred represents the desirable, non-preferred the avoidable, probable the possible, and improbable the impossible. In good life we pursue the preferred, avoid the nonpreferred, and make way for the probable instead of the improbable. Metaphorically, the preferred can be thought as a compass that directs us and helps us avoid walking in circles. 


\begin{tabular}{|c|c|c|c|}
\hline SCHOOL 01-10 & ENVIROMENT 11-20 & LEARNING 21-36 & $\begin{array}{l}\text { UPPER SECONDARY } \\
\text { SCHOOL } 37-48\end{array}$ \\
\hline $\begin{array}{l}\text { SUBJECT-BASED } \\
\text { SCHOOL }\end{array}$ & EU INTEGRATION & ZERO TOLERANCE & PURPOSE \\
\hline ACTIVITY CENTER & E-DEMOCRACY & VIRTUAL REALITY & $\begin{array}{l}\text { WHOLE } \\
\text { AGE GROUP }\end{array}$ \\
\hline META SKILLS & $\begin{array}{l}\text { INTELLIGENCE } \\
\text { MANIPULATION }\end{array}$ & $\begin{array}{l}\text { OUTSOURCED } \\
\text { TEACHING }\end{array}$ & $\begin{array}{l}\text { PRODUCING } \\
\text { INFORMATION }\end{array}$ \\
\hline LEARNING GROUPS & $\begin{array}{l}\text { CONTRIBUTIVE } \\
\text { LEARNING }\end{array}$ & REGIONAL EQUALITY & $\begin{array}{l}\text { RECOGNITION OF } \\
\text { COMPETENCIES }\end{array}$ \\
\hline $\begin{array}{c}\text { SPACE FOR } \\
\text { SLOW LEARNING }\end{array}$ & BUSINESS & $\begin{array}{c}\text { LEARNING } \\
\text { ENVIRONMENTS }\end{array}$ & OPTIONALITY \\
\hline $\begin{array}{l}\text { EDUCATIONAL } \\
\text { OUTCOMES }\end{array}$ & CIVIL SERVICE & KEY COMPETENCIES & $\begin{array}{l}\text { INFORMATION } \\
\text { TECHNICS }\end{array}$ \\
\hline $\begin{array}{l}\text { SINGLE STRUCTURE } \\
\text { TEACHER TRAINING }\end{array}$ & RELIGION & SENIOR CITIZENS & ASSESSMENT \\
\hline COMPETENCE TEST & $\begin{array}{l}\text { COLLECTIVE } \\
\text { INTELLICENCE }\end{array}$ & HOMESCHOOLING & TEACHERSHIP \\
\hline $\begin{array}{l}\text { MULTIDISCIPLINARY } \\
\text { TEACHING TEAM }\end{array}$ & STARTING AGE & $\begin{array}{l}\text { RELEVANT } \\
\text { KNOWLEDGE }\end{array}$ & EFFICIENCY \\
\hline $\begin{array}{l}\text { ENVIRONMENTAL } \\
\text { DEVELOPER }\end{array}$ & TALENT & $\begin{array}{l}\text { SOCIAL } \\
\text { MEDIA }\end{array}$ & GLOBALISATION \\
\hline CARBON FOOTPRINT & SHARED TIME & SELF-EDUCATION & SCHOOL NETWORK \\
\hline COMMUNICATIONS & ENGLISH & $\begin{array}{l}\text { GENERAL } \\
\text { KNOWLEDGE AGENT }\end{array}$ & $\begin{array}{l}\text { ACADEMIC } \\
\text { PATH }\end{array}$ \\
\hline
\end{tabular}

Fig. 1 All the titles of the Future of Learning 2030 Barometer [9, 18], See https://edelfoi.fi/futuriblesoflearning2030

The future of learning is studied through theses on the future of learning, teaching, the school and its environment. Their truth value is open, but they can be assessed and argued both for and against - all of them are possible in some future time. Based on the experts' arguments the theses are divided

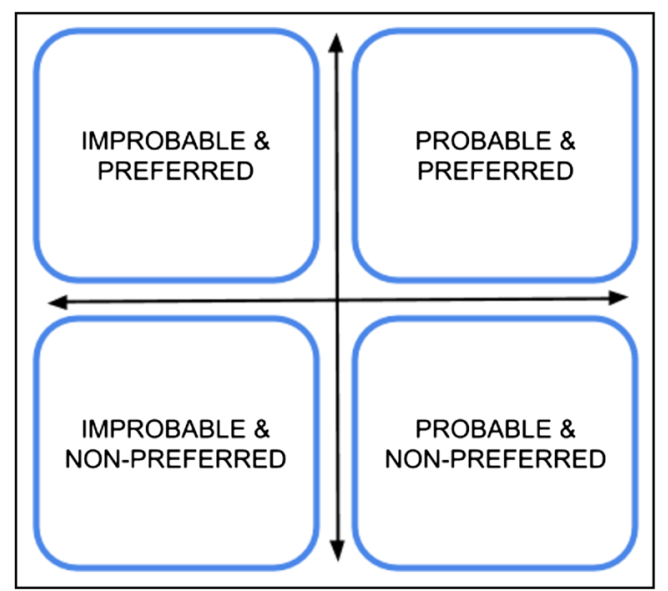

Fig. 2 (1) Probable and preferred (2) probable and non-preferred (3) improbable and preferred, (4) improbable and non-preferred into three positions on the issue: agreement, dialogue, and disagreement (Fig. 3).

A disagreement or opposition begins as a progress that results in a change in the school's paradigm or in a third path that differs from both of the original opposites. A continuing opposition usually opens up discussions, which often diversify and abate opinions. This begins the dialogue phase, where the arguments complement each other in relation to the probable and preferred future. In the agreement phase there is a

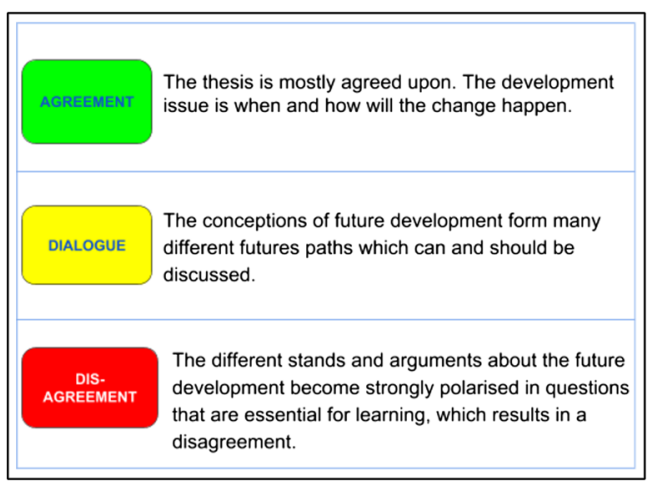

Fig. 3 The three different positions of theses $[9,18]$ 
great consensus on the next position. This does not mean the issue is now settled. A good example of this is the first demonstrated thesis about subject-based school. It has been in the agreement position ever since the beginning even though the current institutions (core curriculum, timetable, teacher education, teacher's job descriptions) are still subject-based.

\section{Theses, themes, and the core curriculum}

The primary benefits of the Barometer are the experts' diverse perspectives and perceptions of future developments. In the empirical section of this article we will introduce three key theses that are in different positions on the issue. These theses signal a wider range of phenomena of change than their concrete content. This relates to the diverse interactions between the changing environment, learning opportunities, and the teaching profession which can be seen in the thesis correlations. Each thesis is first introduced in bold in the same form as the panellists answered it. The footnotes include explanations that specify or concretise the theses or provide background information. The graphics following each thesis show the current position of the thesis. What follows, is a short analysis of the panel's argumentations.

As the amount of material has increased, the theses have been clustered into five thematic categories of model drifts, which are then illustrated as metaphoric futures maps. The thematic categories are based on the contents of the thesis answers as well as their distribution and correlations based on the data from the Barometer. The interaction between the analyses of the Barometer and the curriculum reform process has helped us see the bigger picture behind individual phenomena. In the last subsection we will discuss this national school development process.

\section{Three key theses}

\section{A consensus on transversal studies (Fig. 4)}

"In 2030 the timetable of basic education will be distributed somewhat equally between subject-based (tool and practical subjects) and action-oriented (phenomena, projects, themes) syllabi."4

\footnotetext{
${ }^{4}$ EXPLANATION: Problem-based learning and other multidisciplinary methods have increased in vocational education. The similar "phenomenonbased teaching and learning has its foundation on comprehensive real-world phenomena. The phenomena are explored in their real context, and the related knowledge and skills are studied in multidisciplinary work across individual subjects. The approach is very different from the traditional subject-based school where the studied topics are broken into relatively small and scattered pieces." (phenomenon-based learning, http://ilmiopohjaisuus.ning.com/) In 2030 , the thematic approach to teaching and learning that explores different phenomena in their respective contexts has become an equal part of basic education on all grades alongside the traditional subject-based instruction.
}

The thesis is mostly agreed upon. The development issue is when and how will the change happen.

Fig. 4 Agreement

The thesis on subject-based school does not demand a complete replacement of the current subject-based syllabus with an entirely different way of studying. Instead it calls for supplementing it with more pupil-centred methods. Partly for this reason, the majority of experts $(85 \%)$ find that the realisation of the thesis is both probable and preferred. The amount of disagreeing panellists has decreased during the Barometer, and the thesis is clearly in the agreement position (Fig. 5).

The expert comments support the thesis, but are wary of taking things to extremes. Most panellists emphasised the importance of the medium. "We need both phenomenon-based teaching (e.g. larger multidisciplinary projects) and subjectbased teaching. The latter prepares the pupils to the former. Instead of ruling each other out, they supplement each other." The panellists recognised that needs and possibilities vary in different stages and contents of education. "Tool subjects probably need to be taught also separately so that the pupils learn the basics, but it is not enough for understanding broader topics."

The panellists prefer a phenomenon-based and project-like school, because the related skills are needed in the society and working life. "This is the direction that needs to be taken, if we want the future citizens to manage in the versatile society and world of the future." "Learning that has been 'broken' into subjects simply cannot answer to the complexity of today's working life."

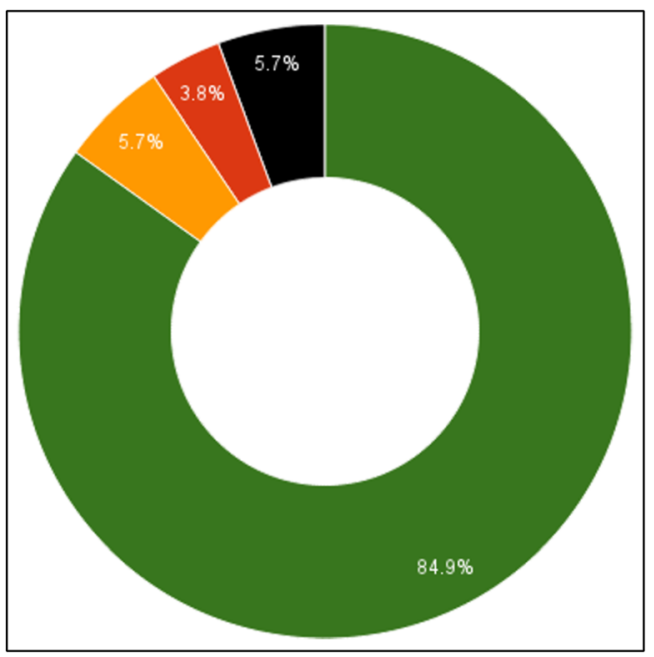

Fig. 5 Probable and preferred=green, Probable and nonpreferred $=$ lighter green, improbable and preferred $=$ orange, improbable and non-preferred $=$ red, borderline cases $=$ black 
Giving up subject-based instruction has a direct effect on the pupils' learning, but at the same time it completely revolutionises the way of teaching. The panellists see future opportunities in "teachers of different subjects working in teams, where multidisciplinary work can create completely new ideas and ways of working. People's creativity can flourish especially when they work together with different people from different fields." Even if subject-based instruction was given up, according to the majority of the panel, the change would be a slow process. The experts agree that the proportion of subjectbased instruction could vary according to the level of education, but they disagree on when this should happen. Others think it should begin already in primary school, but others prefer as late as the university.

If the panel's argumentation had to be summarised in one sentence, it would be this one expert comment: "The world is not subject-based!" This leads easily to another thought, namely that the assessment of an education that aims at preparing the pupils to manage in world cannot rely on a subjectbased final assessment. The next thesis comments on this fundament of the school.

\section{Dialogue on assessment (Fig. 6)}

"The pupil's assessment and given feedback are primarily directed at the meta- and fundamental learning skills, and they take place mostly in the dialogue between the pupil and the teacher."

Whereas the thesis on subject-based school represents the external organisation of the instruction, the meta-skills thesis refers to a change in the internal steering of learning. If either one of these theses come true, they will revolutionise the very basis of both teaching and learning. In the meta-skills thesis, the aim is that the pupil becomes an autonomous and selfdirected learner who receives continuous individual guidance. This aim is so well received the thesis is shifting from dialogue to agreement position (Fig. 7).

According to the thesis, the focus of the pupil's assessment is expected to shift from standardised performance results towards supporting each individual's unique development process and key competences. This also favours a processual

\footnotetext{
${ }^{5}$ EXPLANATION: There is a plan in New Zealand to assess the pupil's progress through five meta-skills: (1) thinking, (2) using and producing language, symbols, and text, (3) identity (managing self), (4) relating to others, and (5) participating and contributing (see New Zealand's Key Competences, http://oraakkeli.blogspot.fi/2009/10/kompetensseilla-uuteen-aikaan.html). In the Finland of 2030, the focus of education has shifted from individual skills and knowledge to more action-oriented competences and meta-skills, which are assessed diversely. In basic education, also the parents participate in the assessment, e.g. via internet. Peer assessment will become more and more important as the studies advance.
}

Fig. 6 Dialogue

vertical assessment instead of the horizontal final assessment [19]. The comments of all panels emphasise the fact that the teaching profession must change in order for the thesis to come true.

The inside panel is worried about problems related to the shift in the focus of assessment: "It is a huge step to change into a new form of assessment that no longer focuses on measuring people's performance from the outside and putting them in order accordingly." The outside panel, then, is concerned whether the assessment will become more subjective than it currently is. How does the assessment take place in the dialogue between teacher, pupil, and parents? What is the role of parents in the assessment of their own children's competence? Many panellists gave the durable advice for the future to avoid sticking to only one type of assessment. "Exaggeration and polarised either-or thinking should be avoided in all development processes. The human cognitive ability is astonishingly diverse. Different competences are needed in different fields. For that reason, there also needs to be different types and objects of assessment that can be applied in different situations."

The experts argue that bulimic learning [20] and memorising meaningless content do not answer the challenges of today. The role of competence is correspondingly considered larger than it is now. Some want to hold on to the

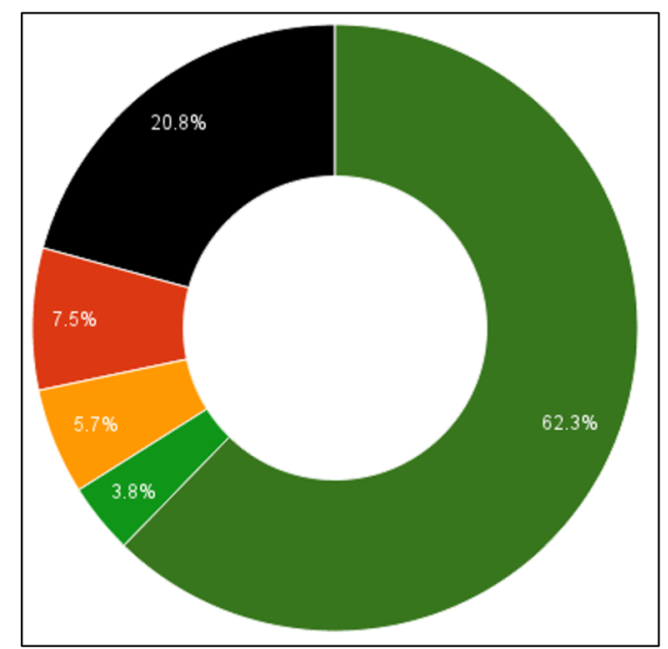

Fig. 7 Two thirds of the panellists agree with the thesis. Less than one tenth disagrees, and one fifth is uncertain. The outside panel finds the thesis slightly more preferred than the inside panel but is more pessimistic about its probability than the inside panel. The support of the thesis has increased in both panels during the Barometer. Probable and preferred $=$ green, probable and non-preferred =lighter green, improbable and preferred $=$ orange, improbable and non-preferred $=$ red, borderline cases $=$ black 
numerical grading system: "The traditional, harsh numerical grading is still needed in the international arenas, when competing, for example, with Asian peers. However, feedback based on strengths is vital. Teachers can include plenty of feedback in their teaching throughout the school year without having to give up the numerical grading."

The outside panel in particular is open for new assessment resources. Many comments mention the importance of technology and peer assessment in the process. Even though assessment is mostly seen as a dialogue between teacher, pupil, and parent, we should increasingly utilise computer-assisted feedback. Sooner or later we will have "convenient technological solutions for process assessment and documentation throughout the school journey as well as for making comparisons and notes, which can be used in later studies for example to trace gaps in earlier studies. The studied contents are integrated with the assessment data, and suitable study exercises and recommendations are allocated automatically according to the gathered data."

\section{Disagreement about the future of collective learning (Fig. 8)}

"Instead of classes or the non-graded model, the pupils are divided into fixed study groups of 6 to 8 people."

The thesis on group learning is the most radical of the examples, and thus its future is disagreed about. Today's school recognises the group as a tool for learning but does not see it as a subject. Group work is used to motivate, to create variation to studying, and to reassert togetherness, but the progress of group learning is not assessed nor are group work skills systematically developed. However, multidisciplinary thematic and phenomenon-based learning signals a change, which could bring a great change to the ways of teaching, guidance, and learning.

The pressure to collective learning comes from outside the school. Working life is based on the ability of teams and organisations to adjust and develop their operations in rapidly changing environments, which are affected by technological development. Many social innovations are based on collective learning, which is also required in the increasing complexity of the environment and the rise of risk levels, as global interdependency increases. The most complex societal problems such as the polarisation of social or economic relations require collective processes with multiple perspectives and dialogue,

\footnotetext{
${ }^{6}$ EXPLANATION: In 2030 working life is almost entirely based on working in teams and the transversal task of the school is to teach the pupils group work skills. The starting point is the definition according to which "teamwork means working in a group or a team that has a shared task and a chance to plan its own work. A group is a community of two or more people that is in continuous interaction or a number of people with common goals." (Statistics Finland, http://www.stat.fi/til/tyoolot/kas.html)
}

Fig. 8 Disagreement

because ready-made knowledge does not lead to solutions [21, 22].

In the Barometer, the panellists' comments on group learning are polarised. There are remarks in both ends of the scale on what could be possible and what should not be given up in any case. Group learning is a key thesis, which has, according to the comments and dialogue, increased both its importance and the difference between the inside and outside panels. The thesis is in disagreement position, even though the amount of dialogue has increased during the Barometer, especially in the outside panel (Fig. 9).

Most arguments are based on benefits: "Teamwork and working together is inspiring in both learning and in working life situations. Together it is possible to make more results in shorter time." Some of the arguments rest on the humanistic view of human nature: "Institutions should 'learn' to make use of people's inherent difference. It is also motivating to be able to use one's talents for common good. Anyway, it would be nice if the school gave more value to cooperation over competition."

The pedagogic comments emphasise the importance of the growth group. The function of the collective is not only to prepare the pupils to future working life or to diversify learning but also to support the pupil's growth process, identity, and self-esteem. "The children of the current era that emphasises individuality should and must be provided with opportunities for social interaction and the peer support that comes with it. A fixed group provides its members with the possibility to grow together as group members. In a heterogeneous group, the stronger members can support the weaker, and the more skilled members can help those who need it."

Learning is motivated by two opposite drivers: competition and cooperation. The latter has an important role in collective learning, which after all is not that significantly different from individual learning. Goal- and result-oriented working is present in all learning and it can be developed systematically through education. However, there are differences between individual and collective learning, which causes problems for the education provider. Traditionally the school has been based on similarities whereas collective learning benefits from differences. This affects also the teaching profession, which has to go through a group formation of its own. The thesis on team teaching is accepted much more readily than the one on group learning.

Individual development processes are a precondition for a collective learning process. Therefore, examining the learning process from an individual point of view is a crucial part of the 
Fig. 9 Probable and preferred $=$ green, probable and non-preferred $=$ lighter green, improbable and preferred $=$ orange, improbable and non-preferred $=$ red, borderline cases $=$ black

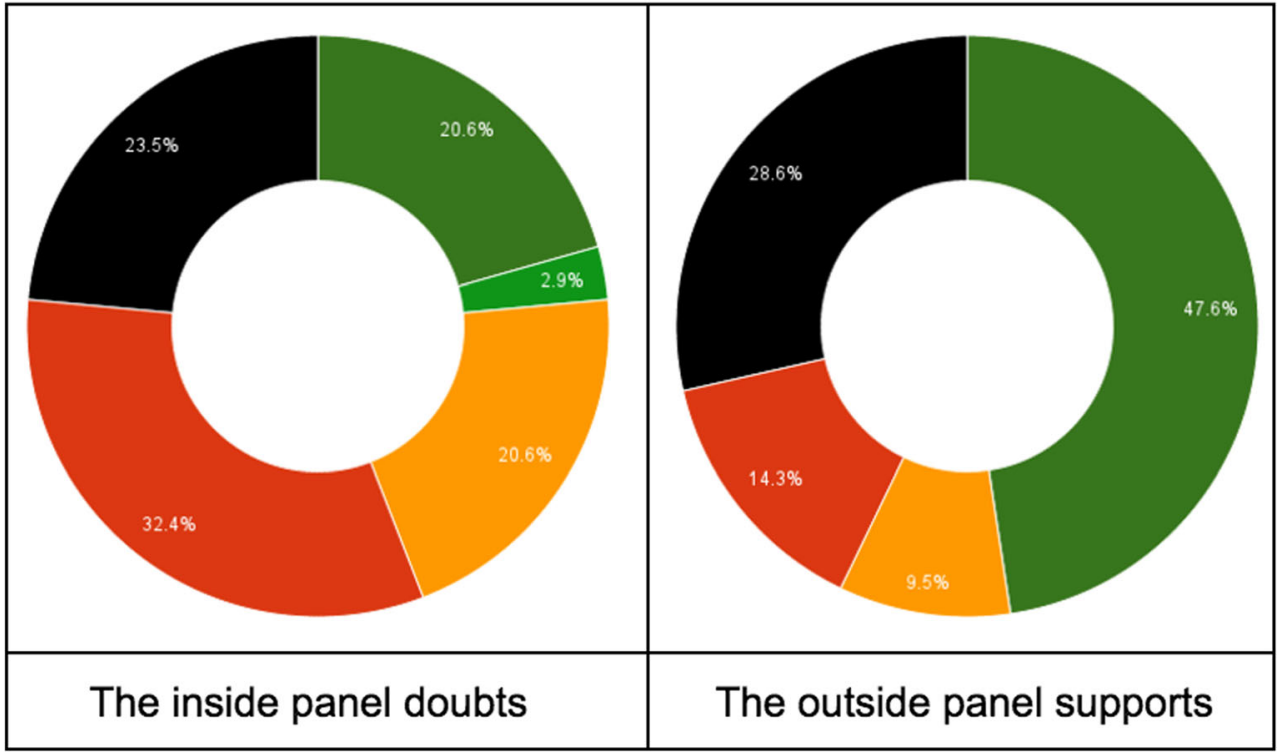

collective learning process. In the future, the school must deploy the knowledge development process in all of its forms, which are intuitive, silent, and explicit [23]. Today's school only attends to the last mentioned. Group learning enables also the other forms as well as the forms of collective learning that occur in communities and organisations larger than teams.

\section{The theses cluster as themes and challenges}

The theses in the Barometer were first created into four categories. The first explores school's values and aims, the second concentrates on the environment and society outside the school, the third focuses on knowledge, skills, and learning, and the fourth examines teaching and the school culture and community. As the amount of data increases, the theses can also be regrouped. The above-mentioned thesis examples form groups with each other and with other theses both statistically (correlations of scale answers) and according to content (argument analysis) and so that meta-theses can be formed. Meta-theses are clusters of theses, and their development is monitored and assessed in the Barometer.

The thesis on subject-based school correlates especially with theses on the future that describe the purpose, aims, and task of the school. The relations seem natural; the school adjusts its operations according to the knowledge, skills, and competences expected of future members of the society. The subject-based school is also connected to the theses that discuss the competences, abilities, and skills learned in school as well as societal relations and the social context. Also the connection to the new competences and cooperation skills required of teachers is central (Fig. 10).

The meta-skills thesis has less connections than the thesis on the subject-based school, but it also has threads to the objectives of learning (competences), the changes of the teaching profession, and the transformation of the forms of learning. All thesis examples have a connection to team teaching, which can be considered the thesis that accelerates the pedagogical remodelling of the school.

The relations of the group thesis strengthen the idea of a paradigmatic thesis that has a strong connection to the task (purpose) of the school as a whole as well as to the assessment of learning and optionality. The panellists' comments correspond with the disciplines of learning organisations. These disciplines suggest that personal mastery should be supplemented with shared vision and mental models as well as team learning and systems thinking [24].

Group learning is a part of a cluster that can be understood as an expansion of the conception of learning. Paavola and Hakkarainen [25] introduce three metaphors for learning. The first is the knowledge-acquisition metaphor and it describes learning as a monologic knowledge formation process that happens in an individual's mind. In the second one, the dialogic participation metaphor, learning is examined as growing as a member of a community. This metaphor emphasises collective learning skills, which help in forming meanings of other people, cultures, and the environment. On top of these two widelyacknowledged learning metaphors, Paavola and Hakkarainen add a third, "trialogic" level of collective knowledge formation, called the knowledge-creation metaphor. It has neither previous structure nor socially shared content. This third metaphor for learning and inquiring is applied in the next subsection.

\section{A metaphoric futures map}

Many independent and conflicting images of the future, which are based on different interpretations of our time, 
Fig. 10 After five years of Barometer, the correlations between the theses were examined for the first time. They showed that the thesis on subjectbased school has connections to exceptionally many other theses

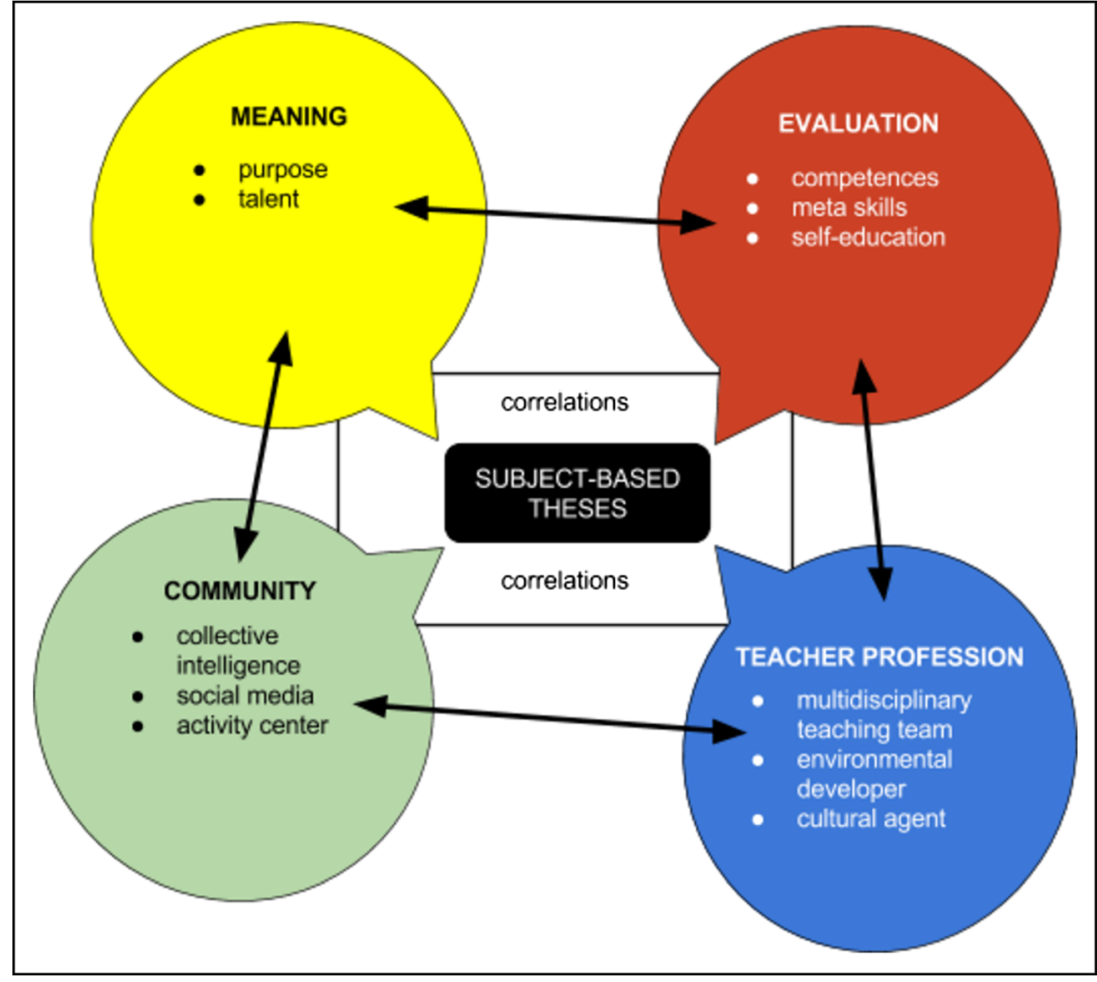

prevail concurrently. On micro-level the individual operators (teachers), on meso-level the organisations (school), and on macro-level the society (education system) all have several images of their own. The most essential questions are, whose image of future on a societal level prevails and how long-lasting the prevailing image is $[9,17]$. When answering the first question, we need to consider values and power relations as well as differences of interest, and in terms of the second question, the rate of the development of phenomena [4]. The material from the Barometer enables the examination of both questions, and Causal Layered Analysis (CLA) is used to further advance the examination. CLA combines three different approaches (empirical, interpretive, and critical) that primarily produce different presumptions about operators, reality, and future.

Future developments can be foreseen by detecting the distributions of the theses and changes in the time series (empirical approach). In the thesis analyses the distribution data is combined with the arguments and contextualised meanings. The result is the interpretive approach. In a critical inspection, the interpretations are compared to the historically formed institutional development, which always relates to power and the right to determine what knowledge is significant at a given time. The critical futures research conducted in the Barometer is soft and processual. It is not based primarily on a critical inspection of the existing world but on outlining the formation of futuribles. However, it is a critical approach, as it is based on a paradigmatic change. The used method is a metaphoric futures map [26].
The metaphoric futures map is not so much a foresight model as a map and coordinate platform for alternate futures. The map is dynamic as it is projected with the changes, shifts, and relations of the Barometer data. This kind of a dynamic and empirically-based futures map is a tool for evoking discussion, strengthening futures thinking, and laying a foundation for policy making. This way, we are able to discover also those futuribles that are formed differently and with a different logic than our current reality.

Therefore, the metaphor is used to clear the way for such futuribles of the school and learning that cannot be derived directly from tradition or the current state. The metaphoric descriptions are indicative and easily modified, if the data gives reason for it. Even if the possible futures are weak, the metaphors can clear the way for discussion and argumentation, which are usually dominated by institutional points of view that are anchored to the interests of the near future. The unrealised options have no strong supporters, but they become stronger if their deviant rationality can be explained with a metaphor.

\section{Five mountains, five themes}

The metaphors in the Barometer have an empirical foundation upon which narrative layers are built $[17,27]$. There are both qualitative and quantitative connections between the theses, and according to these connections, the theses have been divided into systemic theme categories. Based on the relations, the first metaphoric futures map has been created, and it will 
develop, improve, and expand alongside the Barometer process (Fig. 11).

At the time of its creation, the futures map is a basic twodimensional map with symbols also for a third dimension. The topography, or contour lines, describes the features of the surface. This expands the map metaphor to transformations, which are characteristic of change processes. A typical change begins with a technological innovation that opens up new possibilities. Sooner or later this leads to a social re-organisation. It is not until the final stage of the change that new ideas form a definite rationality that replaces the former logic of action. In the Barometer, the metaphor is used to outline the possible formation of the logic in the final stage as well as its outcomes. The Barometer data is meant to verify and falsify the formation of the logic.

The five mountains in the metaphor represent the five clusters of challenges in the future of learning that need to be resolved in the following years or decades. Both of their solutions require the re-organisation of learning and the remodelling of the ideas behind learning. On the futures map, learning creates many paths to different directions. As learning becomes more personalised but at the same time more collective, also teaching has to change and the school will become more connected to external possibilities and resources than it currently is. While the traditional school aims at acquiring knowledge, the changing world creates a need to concentrate on competences [27].

The first mountain is the challenge of personalising and liberating learning without losing the resources of the uniform, high-quality, and equal Finnish school [28]. Today's school is based on a teaching-driven logic, which learning has had to adapt to. In terms of the teaching profession, the ideal situation has been a group of learners with similar competence levels, educational-psychological profiles, and motives. There will be a change as teaching begins to increasingly adapt to the learners' characteristics and to recognise better the different forms, needs, and goals of learning. A modern challenge is to enable individually adapting learning in heterogeneous groups without increasing costs. In the Barometer, the personalisation of learning is addressed through theses related, for example, to the decline of subject-based school, to adapting learning to the learners' talents, to the increasing use of virtual environments as well as to collective knowledge production,

\section{Futures map: LEARNING 2030}

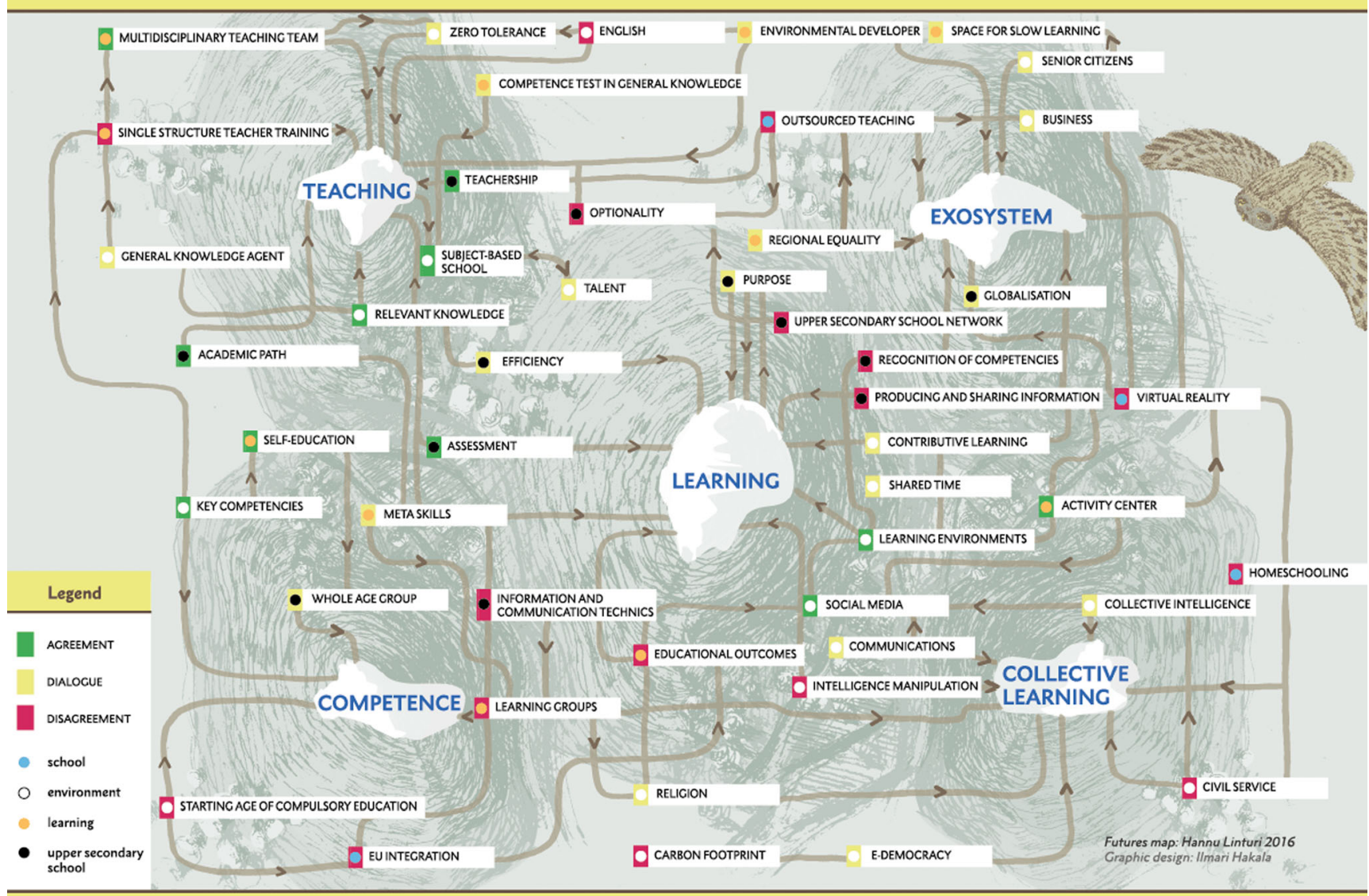

Fig. 11 A set of five developing fold mountains have been drawn on the futures map of learning. They illustrate meta-changes in which the logic of the activity changes, and institutions alongside it 
which has already become a part of daily school life in the form of social media. Most panellists estimate that a big change in the forms of learning has already happened by 2030 .

The meta-change in learning causes a second challenge for future learning, namely the metamorphosis of the teaching profession. The focus shifts from teaching contents towards guidance, assessment, and the management of learning environments. As the subject-based school moves towards projectlike learning, the ways of demonstrating competences diversify. This forms a basis for lifelong autonomous learning, and at the same time, also the teaching profession changes. The metamorphosis of the profession is the basis of the timing of all other mountains. It determines whether the change sneaks in quietly or barges in with a bang. In the Barometer, the change in the teaching profession and the multiprofessional nature of future learning are indicated by theses related, for example, to encountering and assessing the pupils and organising the practicalities of teaching as well as to teacher education.

The second challenge opens the door for a third challenge, that is, the reassessment of the resources used to learning processes. The school as a learning environment becomes an exosystem that makes use of many resources from inside and outside the school that have not been used before. The traditional school is tied to time and location. The internet, however, fades the boundaries of both of them. The limits of the school are expanded and doors are opened to outside expertise as the teaching teams focus on diversifying the ways of learning. At times learning takes place in different authentic and virtual environments. The school becomes "the headquarters" of all learning that serves the local community and brings local operators close to different development projects. In this idealised model, individual learning blends in with collective goals, which validates participation. In the eyes of the panellists, the school of the future has stronger and different ties to the society than the school of today. The school's closed "ecosystem" becomes an open "exosystem" that welcomes different collaborators into school work. These include parents, operators in the third sector, local administrators, senior teachers, businesses and, interestingly enough, the artificial intelligence.

There is a change in motion in the contents of general knowledge, and it is essential for the school. They are understood more dynamically than before as preconditions for different skills and as key competences rather than static information contents. Over the past ten years, there has been a growing sense of the need to redefine general knowledge. International organisations (OECD, EU) that study education and learning with relation to the economy and working life have had an active role in this initiative. According to the Barometer, the transition to the competence-based school requires comprehensive revision of the contents and working methods of the school. The development is indicated with theses related, for instance, to the preconditions of competence-based teaching and learning as well as the society's efforts to develop the nation's competence with education policies.

The globalising working and citizen life signals a need to extend the concept of learning to be understood as a characteristic of groups, communities, and cultures. The fifth learning challenge is to institutionalise the different forms of $\mathrm{col}$ lective and group learning. In its current state group work and collective learning is mostly as unorganised activity, which highlights the differences between the learners instead of utilising the different competences and interests as a resource. The personalisation of learning compliments collective learning, as the pupils acknowledge their own uniqueness and find important roles in group activities with shared goals. The theses in the Barometer comment, for example, on team-based learning groups, the development of communities' intelligent and sustainable operations as well as the role of social media in learning. The thesis cluster of collective learning also links the Barometer to active citizenship through theses, for example, on digital democracy, environmental issues, and collective participation.

\section{The challenges and needs of the curriculum}

In the curriculum reform process led by the FNBE, a firm knowledge base, and future visions were created by analysing the results of various research, evaluations, and development projects - both domestic and international - and by active knowledge-sharing and transparent dialogue with all those involved and affected by the change. More than 300 people participated in the working groups which created the national core curriculum. Hundreds of other experts were heard, including researchers and representatives of civil society organisations and working life. Thousands of people were involved in the process through digital networks. As a result of the collaborative process, people could make sense of the reform and reflect on how it benefits their own work and life [29]. The process produced the national core curriculum for basic education [30] of which municipal authorities, teachers and parents feel ownership and, therefore, to which they are committed. Amazingly enough, the curriculum reform has been reflected mainly positively also by the media. For instance, in its leading article the main newspaper of Finland described the starting point of the reform excellent because it is based on trusting teachers and emphasising their pedagogical autonomy as well as promoting students' active role in learning [31].

In the design process of the national core curriculum the FNBE wanted to deal with past, present, and future in order to learn from the past, to be resilient with the present challenges, and to envision the futuribles [32]. The Barometer was 
especially valuable in reflecting the challenges and possibilities of the future. The theses of the Barometer included various themes of the near and even more remote future which the new core curriculum was expected to take into account and find the best possible guidelines for proceeding towards the future. The issues produced by the Barometer were brought to be discussed in the curriculum groups and various seminars and conferences. People were asked to express their expectations, worries, and dreams concerning the future of education as well as to reflect on the connections and interdependencies between the school and the society. Reflections were also needed on the nature of learning. Learning seems to come increasingly ubiquitous. It crosses the boundaries between formal and informal, local and global, physical and virtual [33].

The discussions were fruitful and supported the design process of the core curriculum. Based on the feedback received by the FNBE, the process was regarded as successful and productive. It was meaningful for the participants, and as a result, the produced national guidelines enhance well the rethinking of the education system, school culture, and teaching and learning processes, as well as the meeting of the challenges of the future.

The challenges reflected in the curriculum process had close connections to the theses of the Barometer. These included especially issues such as

- Changing roles of teachers and students - focus on guidance and support in teaching as well as on active and participatory approach in learning

- Crossing boundaries between the society and the school, active cooperation, and ability to find appropriate partners as well as to utilise the expertise and other resources offered by the surrounding society

- Crossing boundaries inside the school - strengthening of the collaborative, multidisciplinary, and multiprofessional approach, developing the schools as a learning community

- Focusing on transversal competences in teaching and learning $[27,34]$.

\section{Discussion and the future of the study}

The new curricula were put into operation in the beginning of August 2016. The Future of Learning 2030 Barometer moved from the preparation of the curriculum to monitoring its implementation, but the target year is still 2030. By then, the pupils beginning their education according to the new curricula will offer their competences to working and citizen life. The questionnaires will be updated so that the panellists will evaluate two to four new theses on topics that have risen during the Barometer and the curriculum reform process.
The analyses will be reviewed annually as the data evolves. It is interesting to observe the trend of the early years where the main panels of the Barometer have chosen a different path in many questions about the future of the school.

The experts from outside the school believe increasingly in new solutions and possibilities. They are also more prepared to change the operating methods and structures of the school than the inside panellists. In the inside panel, then, the doubt about changing the school has increased somewhat. Perhaps they are concerned about the threat to the undeniable achievements of Finnish basic education caused by the recent developments and increasing differences between schools. On a large scale, concerns are turned into solutions also in the inside panel. Attitudes have already changed so that the narrow conception of teaching is being replaced with a diverse conception of learning. It is no longer enough to concentrate to just one type of learning situation and its management, when learning is understood as ubiquitous and all pupils as different kinds of learners.

The panellists' perceptions change in time as the world changes and new ideas develop. One development path opens and other closes, and a third becomes more winding than what was foreseen. Disagreements become discussions, and discussions result in agreements. As one questions gets answered, another gets raised. The Barometer is planned to continue at least until 2020, when we might already see some answers beginning to form in the large questions concerning school and learning. How can we maintain equal opportunities in the society if and when learning paths become more diverse and personalised? How do we answer the challenge collaborative working approaches pose to the school system? To what extent will the teaching profession transform? What will brain and neuroscience bring to learning, and will intelligence move from organisms to artificial life? The modern industrial times separated the school from the rest of the society and placed different age groups in different classrooms. Will the postindustrial time return educational institutions to their authentic contexts, and will schools become "the centres of the town" once more? Will knowledge develop into understanding and skills into competences?

Even after the curriculum reform 2016, the Barometer can be used as a tool for making decisions of today from the perspective of the future needs. We need to look further, because close vision is blurred by different interests which are monitored effectively in a highly organised country like Finland. In addition, the Barometer form helps us recognise future turning points and changes in development that cannot be detected by observing trends. Basic education that covers the entire age group is an institution whose changing process is the most demanding as possible. Roughly speaking, the school system has the ability to make the society either more or less layered. The central idea of the Finnish school has been to provide the needed education for every child regardless of 
their place of birth or the area they live in. It means providing equal opportunities for the pupils by trying to even out the differences that exist already before basic education.

The difference between the two main panels can be interpreted to represent a situation where the increased opportunities of learning are at risk of materialising in ways that increase inequality between pupils as a by-product. This risk is strengthened by the changes in the school's operating environment. Population development has been concentrated, and areas in large cities become increasingly differentiated. This has also increased the amount of school choices that reinforce differences between different areas. One of the largest challenges in navigating the future is to realise the school's new possibilities without increasing the differences between the pupils' future opportunities. Even in ideal conditions, the future potential does not automatically distribute evenly [19]. The school is needed to balance the situation where some have better opportunities than others to make sustainable choices for their future.

In financial terms, the pre-primary and basic education is an investment that can bear interest for the society for tens of years. However, it is not merely a question of stakes but also about the way of doing things. Here, we can use the following metaphor: A race driver learns to optimise the course of the car by pressing the accelerator and the brakes at the same time. The Barometer can be read so that, in school, technology presses the accelerator and pedagogic the brakes. Both are needed, if the road towards the future is winding. The same global challenges face Finland as many other European countries, but we also have some specific problems. The education budget has been cut more compared to many other countries, and it remains to be seen whether the renewal capacity is strong enough to beat the negative effects of the cuts.

The Barometer process makes use of information on the implementation of the new curricula in schools around Finland. The orderer of the Barometer, The Finnish National Board of Education, gathers information on the curriculum reform process and the implementation of the core curricula in municipalities and schools. The Ministry of Education has assigned the actual assessment task to the Finnish Education Evaluation Centre and a research group that represents three different universities [29]. The assessment focuses on the achievement of the reform's central objectives as well as on possible factors standing in the way of their achievement.

Open Access This article is distributed under the terms of the Creative Commons Attribution 4.0 International License (http:// creativecommons.org/licenses/by/4.0/), which permits unrestricted use, distribution, and reproduction in any medium, provided you give appropriate credit to the original author(s) and the source, provide a link to the Creative Commons license, and indicate if changes were made.

\section{References}

1. EU Commission (2016) A new skills Agenda for Europe: Communication from the Commission to the European parliament, the council, the European economic and social committee and the committee of the regions. COM 381. https://ec.europa. eu/transparency/regdoc/rep/1/2016/EN/1-2016-381-EN-F1-1.PDF Accessed 21 October 2016

2. Halinen I, Niemi H, Toom A (2016) La confiance, pierre angulaire du système éducatif en Finlande. Revue Internationale d'éducation de Sèvres 72:147-157

3. de Jouvenel B (1964) L'art de la conjecture. Editions du Rocher, Monaco

4. Rubin A (2013) Skenaariotyöskentely tulevaisuuksien tutkimuksessa. Metodix. https://metodix.fi/2015/01/31 /skenaariotyoskentely-tulevaisuuksientutkimuksessa/ Accessed 21 October 2016

5. Bishop P, Hines A, Collins T (2007) The current state of scenario development: an overview of techniques. Foresight 9(1):5-25. doi:10.1108/14636680710727516

6. Kuusi O, Hiltunen E, Linturi H (2000) Heikot tulevaisuuden signaalit - Delfoi-tutkimus (Weak signals: a Delphi Study). Futura 14(2):78-92

7. Inayatullah S (2005) Causal layered analysis - deepening the future. questioning the future. methods and tools for organizational and societal transformation. Tamkang University Press, Tamsui. http://www.metafuture.org/cla\%20papers/Inayatullah\%20 Causal\%201ayered $\% 20$ analysis $\% 20-\% 20 \% 20$ Deepening $\% 20$ the\%20Future.pdf Accessed 21 October 2016

8. Inayatullah S (2014) Causal layered analysis defined. The futurist. World Future Soc 48(1):26

9. Linturi H, Rubin A (2011) Toinen koulu, toinen maailma. Oppimisen tulevaisuus 2030. Tutu-julkaisuja. Turku university, FFRC, Turku

10. Kuusi O (1999) Expertise in the future use of generic technologies. VATT-research, Helsinki, p 59

11. Laakso K, Rubin A, Linturi H (2011) The role of regulation in mobile operator business in Finland. Foresight: J Future Stud, Strat Think Policy 14(2):157-164

12. Linturi H (1998) Professional Delphi scan. Käyttäjän ja managerin opas. Turku university, FFRC, Turku

13. Linturi H (2007) Delfoin metamorfooseja. Futura 1:102-114

14. Linturi J, Linturi H, Rubin A (2010) Delfoi siltaa rajanylityksiä. Uudistuva aikuiskoulutus. Tutkimuksia MAMK, Mikkeli 49:115335

15. Tapio P (2003) Disaggregative policy Delphi: using cluster analysis as a tool for systematic scenario formation. Technol Forecast Soc 70(1):83-101

16. Turoff M, Linstone H (2002) The Delphi method. techniques and applications. http://is.njit.edu/pubs/delphibook/ Accessed 21 October 2016

17. Linturi H, Rubin A (2014) Metodi, metafora ja tulevaisuuskartta. Futura 33(3). https://metodix.fi/2014/11/26/metodi-metafora-jatulevaisuuskartta/ Accessed 21 October 2016

18. Linturi H, Rubin A, Airaksinen T (2012) Toinen koulu, toinen maailma. Lukion tulevaisuus 2030. Tulevaisuus, Pedagogia 2/ 2011. Otava Cooperative. http://www.oph.fi/julkaisut/2011 /lukion tulevaisuus_2030

19. Rubin A, Linturi H (2001) Transition in the making. the images of the future in education and decision-making. Futures 33:267-305

20. Coffield F et al (2014) Beyond Bulimic learning. improving teaching in further education. IOE Press, London

21. Hämäläinen TJ, Heiskala R (2004) Sosiaaliset innovaatiot ja yhteiskunnan uudistumiskyky. Edita Publishing, Helsinki 
22. Scharmer CO (2009) Theory U: leading from the future as it emerges. Berret-Koehler Publishers, San Francisco

23. Korhonen-Yrjänheikki K (2011) Future of the Finnish engineering education: a collaborative stakeholder approach. Dissertation, Aalto University, Academic Engineers and Architects in Finland - TEK

24. Senge P et al (2012) Schools that learn (updated and revised): a fifth discipline fieldbook for educators, parents, and everyone who cares about education. Crown Religion/Business/Forum

25. Paavola S, Lipponen L, Hakkarainen K (2004) Models of innovative knowledge communities and three metaphors of learning. Rev Educ Res 74:4557-4576. doi:10.3102/00346543074004557

26. Malamud C (2014) A Shared Reality. MappaMundi. http://mappa. mundi.net/cartography/Maps/ Accessed 21 October 2016

27. Futura (2014) Oppimisen tulevaisuus 2030 (Future of learning 2030). Futura 3(2014)

28. Linturi R et al (2014) 100 Opportunities for Finland and the World. Publication of the Committee for the Future, Helsinki. https://www. eduskunta.fi/FI/tietoaeduskunnasta/julkaisut/Documents/tuvj_11 +2014.pdf Accessed 21 October 2016
29. Pietarinen J, Pyhältö K, Soini T (2016) Large-scale curriculum reform in Finland: exploring the interrelation between implementation strategy, the function of the reform, and curriculum coherence. Curriculum J Routledge. doi:10.1080/09585176.1179205

30. FNBE (2014) National core curriculum for basic education 2014. The Finnish National Board of Education, Helsinki

31. Helsingin Sanomat (2016) Suomi voi olla ylpeä opettajistaan (Finland can be proud for its teachers). http://www.hs. fi/paakirjoitukset/a1464758422984 Accessed 21 October 2016

32. Engeström Y (2015) Learning by expanding: An activitytheoretical approach to developmental research, 2nd edn. Cambridge University Press, Cambridge

33. Krokfors L et al (2015) Learning. creatively. together: educational change report 2016. Faculty of Behavioural Sciences, University of Helsinki

34. Futura (2015) Koulun tulevaisuus 2030 (Future of school 2030). Futura 2(2015) 